\title{
Spatial distribution of the upside-down jellyfish Cassiopea sp. within fringing coral reef environments of the Northern Red Sea: implications for its life cycle
}

\author{
Wolfgang Niggl $\cdot$ Christian Wild
}

Received: 10 July 2009 / Revised: 4 November 2009 / Accepted: 9 November 2009 / Published online: 26 November 2009 (C) Springer-Verlag and AWI 2009

\begin{abstract}
The zooxanthellate mangrove jellyfish Cassiopea sp. represents a prominent invasive species and a potential bioindicator for nutrient monitoring in coral reefs. However, information about its spatial distribution in combination with abundance, habitat specificity and life cycle elements is barely available. This study, therefore, presents the results of field surveys conducted within four different benthic habitat types (coral reef, seagrass meadow, reefsand transition and sand flat) in the Northern Red Sea. Cassiopea $\mathrm{sp}$. exhibited a highly patchy distribution within the entire study area with mean abundance of $1.6 \pm 0.3$ animals $\mathrm{m}^{-2}$ and benthic coverage of $3.2 \%$. Within coral reef habitats, maximum abundance of up to 31 animals $\mathrm{m}^{-2}$ and benthic coverage of up to $20 \%$ were detected. Additionally, this study revealed that $65 \%$ of all observed Cassiopea specimens were associated with the commensalistic crustacean mysid Idiomysis tsurnamali. Cassiopea abundance and size as well as association patterns with mysids differed between most of the surveyed habitats. In summary, the findings of the present study (1) characterize Cassiopea as one of the key organisms in investigated benthic habitats, (2) indicate active habitat selection by the jellyfish and (3) may hint to an unexplored life cycle of Cassiopea with central role of seagrass meadows providing cues for larval settlement and metamorphosis in the absence of mangroves.
\end{abstract}

Communicated by H.-D. Franke.

W. Niggl $(\bowtie) \cdot$ C. Wild

Coral Reef Ecology Group (CORE),

GeoBio-Center and Department of Earth and Environmental

Science, Ludwig-Maximilians Universität,

Richard-Wagner-Str. 10, 80333 München, Germany

e-mail: w.nigg1@1rz.uni-muenchen.de
Keywords Cassiopea - Abundance - Coral reef . Benthic habitat $\cdot$ Idiomysis tsurnamali $\cdot$ Life cycle

\section{Introduction}

Cassiopea sp., commonly referred to as mangrove or upside-down jellyfish, represents a study organism within several scientific disciplines. Interorganismic interactiontypically an ecological topic_-such as the jellyfish's symbiotic relationship with dinoflagellates or the commensalistic relationship with the crustacean mysid Idiomysis tsunrnamali (Bacescu 1973) has been addressed by marine scientists from various fields (e.g. Bacescu 1973; Hofmann and Kremer 1981; Thornhill et al. 2006). The lifecycle of the scyphozoan Cassiopea is classically metagenetic and, therefore, alters between a medusoid and polypal stage, with an intermediate larval stage (e.g. Bigelow 1900; Gohar and Eisawy 1960b; Smith 1936). Many studies have focused on factors influencing the development of Cassiopea, dealing with endogenous (Thieme and Hofmann 2003a, b) or exogenous (e.g. Bischoff et al. 1991; Curtis and Cowden 1971; Fleck and Fitt 1999; Fitt and Costley 1998; Hofmann et al. 1978) cues for larval settlement and metamorphosis, as well as factors influencing strobilation (e.g. Fitt 1984; Hofmann and Kremer 1981; Ludwig 1969; Rahat and Adar 1980). Additionally, the upside-down jellyfish has drawn attention as a possible bioindicator species for low-nutrient environments. In this context, Todd et al. (2006) demonstrated the potential of Cassiopea sp. as a susceptible indicator species for environmental phosphates.

However, information about its spatial distribution in combination with abundance is barely available. Holland et al. (2004) described Cassiopea as globally distributed, occurring in shallow, tropical inshore marine waters on 
sandy mudflats. Reports on remarkably high Cassiopea abundances, e.g. in the Caribbean and the Red Sea, were first summarized by Mayer (1910). However, quantitative data are only provided by Collado Vides et al. (1988) for the Nichupte lagoon system off the Mexican Caribbean coast and by Mergner and Schuhmacher (1981) for a $25 \mathrm{~m}^{2}$ seafloor patch in the Northern Red Sea. Recently, a Cassiopea sp. was reported to increase its spatial distribution by invading into, for example, Hawaiian and Mediterranean waters (Çevik et al. 2006; Holland et al. 2004; Özgür and Öztürk 2008; Panucci-Papadopoulou et al. 2005). As invasive species are a principle threat to biodiversity and responsible for enormous economic losses (Bolton and Graham 2006), and especially jellyfish are known for their direct negative effect on human enterprises (Purcell et al. 2007), alterations in distribution and abundance of Cassiopea sp. require monitoring.

The present study, therefore, aims to provide data on abundance, habitat selection and life cycle elements like size classes and the commensalism with Idiomysis tsurnamali for Cassiopea in Northern Red Sea fringing reef environments. It thereby aims to contribute to understand the ecology of the jellyfish and to deliver a dataset for further monitoring. For this purpose, a study area in the Northern Gulf of Aqaba, Jordan, comprising several different benthic habitat types, was surveyed using two transect techniques and subsequent digital image as well as statistical analyses.

\section{Materials and methods}

\section{Description of study site}

The study was conducted in May 2008 in the Northern Gulf of Aqaba at the marine reserve of the Marine Science Station (MSS), Aqaba, Jordan ( $\left.29^{\circ} 27^{\prime} \mathrm{N}, 34^{\circ} 58^{\prime} \mathrm{E}\right)$. All surveys took place at water depths of 5 to $20 \mathrm{~m}$ in a study area located directly north of the MSS jetty, ranging from $50 \mathrm{~m}$ north and $50 \mathrm{~m}$ south relative to the coordinates $29^{\circ} 27^{\prime} 31^{\prime \prime}$ $\mathrm{N}, 34^{\circ} 58^{\prime} 34^{\prime \prime} \mathrm{E}$ (Fig. 1). Because surveys for the present study took place only during one season, and jellyfish blooms may occur seasonally (Mills 2001), supporting semiquantitative data from other investigations during other seasons and years, but at identical study site, were collected. These data are summarized in Table 1 and confirm that the observations displayed in the present study are not atypical.

\section{Benthic composition}

Benthic composition of the study area was determined using $50 \mathrm{~m}$ line point intercept (LPI) transects (modified after English et al. 1994) with recording intervals of $1 \mathrm{~m}$. These transects were conducted at 5.0, 7.5, 10.0, 12.5, 15.0

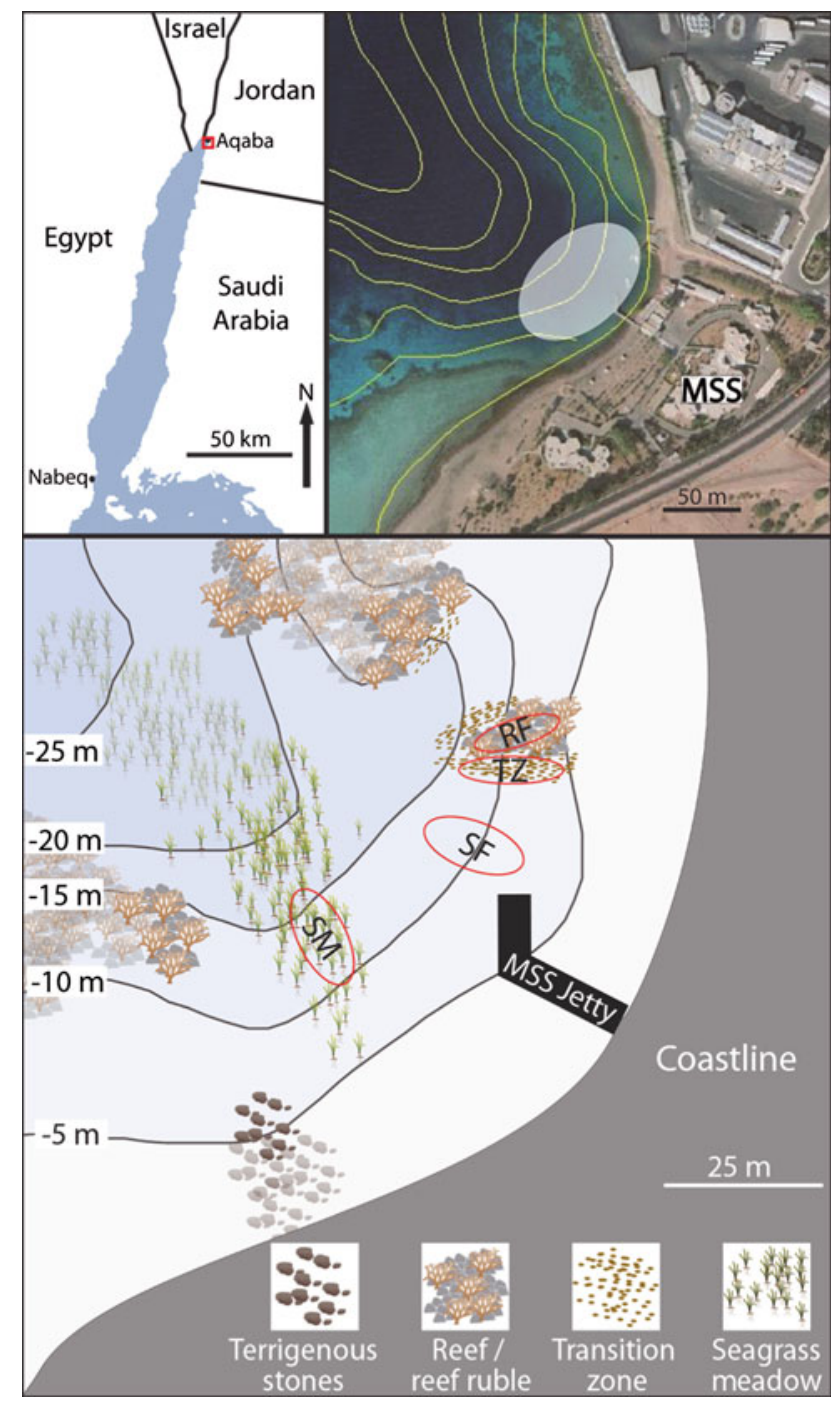

Fig. 1 Map of the Gulf of Aqaba (top left). Aerial image (property of Aqaba Special Economic Zone Authority) of the Marine Science Station (MSS) in Aqaba with the study area indicated by transparent ellipses (top right). Benthic composition of the study area revealed by line point intercept transects (bottom). No transect-derived data were recorded in areas indicated by transparent icons. Red ellipses indicate distinguished main habitats ( $R F$ reef, $T Z$ transition zone, $S F$ sand flat, $S M$ seagrass meadow)

and $20.0 \mathrm{~m}$ water depth each to the north and the south of the MSS jetty. Sediment type and seafloor coverage by benthic fauna and flora were recorded to get an overview of occurring benthic habitats in the study area. LPI transects revealed four distinct, main habitats: (a) the reef habitat, which describes the patchy reef northern of the MSS; (b) the sand flat consisting predominantly of silicate sands (Wild et al. 2005); (c) the transition zone, which is located between the reef habitat and the sand flat and (d) the seagrass meadow. These four habitats were examined for habitat-specific Cassiopea abundance and size dimensions as well as association with mysids (see below). Results of 
Table 1 Summary about previous and successive observations of high Cassiopea abundances ( $>5$ animals $\mathrm{m}^{-2}$ ) in benthic habitats identical to those investigated in present study during spring 2008

\begin{tabular}{lll}
\hline Year & Season & Observer \\
\hline 2002 & Spring & E.M. Zetsche \\
2004 & Spring & C. Jantzen \\
& Summer & C. Jantzen/C. Wild \\
& Autumn & M. Naumann \\
2005 & Winter & M. Naumann \\
2006 & Autumn & C. Jantzen/C. Wild \\
2007 & Summer & C. Wild \\
& Autumn & C. Jantzen \\
2008 & Winter & C. Wild/W. Niggl/A. Haas \\
& Summer & L. Kamphausen \\
\hline
\end{tabular}

Holland et al. (2004) indicate that the species investigated by the present study was likely Cassiopea andromeda. However, as no molecular analysis was performed and determination of species affiliation based on morphology is rather vague within the genus Cassiopea (Holland et al. 2004), in the following, the generic notation Cassiopea sp. was used.

\section{Cassiopea sp. abundance}

In order to determine average abundance of Cassiopea sp. (specimen $\mathrm{m}^{-2}$ ) within each benthic habitat type, multiple single quadrate surveys were conducted. Thereby, a quadrate of $1 \mathrm{~m}$ side length was randomly placed on the seafloor at $13 \mathrm{~m}$ water depth. Subsequently, the quadrate was flipped over towards a more shallow area, and again the number of abundant Cassiopea sp. was recorded. This was repeated until a water depth of $7 \mathrm{~m}$ was reached. With this preset methodology, subjective placement on obviously high abundance spots was avoided. This procedure was carried out on all four distinguished main habitats except the seagrass meadow, where due to its spatial extensions (upper limit at $10 \mathrm{~m}$ water depth), the survey was conducted between 16 and $10 \mathrm{~m}$ water depths. The abundance of Cassiopea sp. in all 14 to 23 resulting replicate quadrates was recorded, and a photograph taken from directly above using a Panasonic TZ5 (9.1 megapixel) digital camera with underwater housing. There was no correlation $(P=0.44$; Spearman rank-order correlation) between Cassiopea abundance and water depth, so that the slightly deeper benthic habitat seagrass meadow could be compared to the other habitats.

Cassiopea sp. abundance was related to the entire study area by multiplication of habitat-specific mean abundance and proportional seafloor coverage of each habitat.

Maximum abundance of Cassiopea sp. in each habitat was quantified by placing quadrates specifically at spots with high Cassiopea sp. abundance. This procedure was repeated within each of the four habitat types at least 10 times, and maximum abundances were recorded from these subjective assessments.

\section{Cassiopea sp. benthic coverage}

Benthic coverage of Cassiopea sp. as well as the proportion of unoccupied sand flats in the four habitats was analysed using the image processing software ImageJ on digital photographs of the single quadrate surveys (see above) using the quadrate side length of $1 \mathrm{~m}$ as a scale. Maximum benthic coverage at each habitat was analysed accordingly using the pictures from maximum abundance determination (see above). Benthic coverage of Cassiopea sp. in the entire study area was calculated from the data obtained by LPI transects.

\section{Cassiopea sp. size and association with Idiomysis tsurnamali}

Cassiopea sp. specimens at all four habitats were also parallel surveyed concerning jellyfish diameter and association with Idiomysis tsurnamali. Specimens $(n=22$ to 36 per habitat) were randomly selected, and their oral surface diameters were measured using a ruler (accuracy: $\pm 0.1 \mathrm{~cm}$ ). All specimens were also examined for the occurrence of associated Idiomysis tsurnamali (Fig. 2a), and the swarm size of the mysids was estimated using the categories described in Table 2.

\section{Statistical analysis}

In order to investigate habitat-specific differences in jellyfish diameter, one-way ANOVAs followed by a LSD post hoc test were carried out. One-way ANOVA was chosen as the parameter "jellyfish diameter" was independent within and between samples. In contrast, due to the "end to end" placement, quadrates of the habitat surveys and resulting data for Cassiopea abundance and benthic coverage were not independent. Hence, these parameters were tested for habitat-specific differences using Mann-Whitney $U$ tests. All categorical data (e.g. mysids size categories) were converted into discrete data and tested using Mann-Whitney $U$ tests. Correlations were tested using the Spearman rankorder correlation.

\section{Results}

Benthic composition

Sand flats, consisting of predominantly silicates sands, dominated the study area, comprising $60.2 \%$. However, 

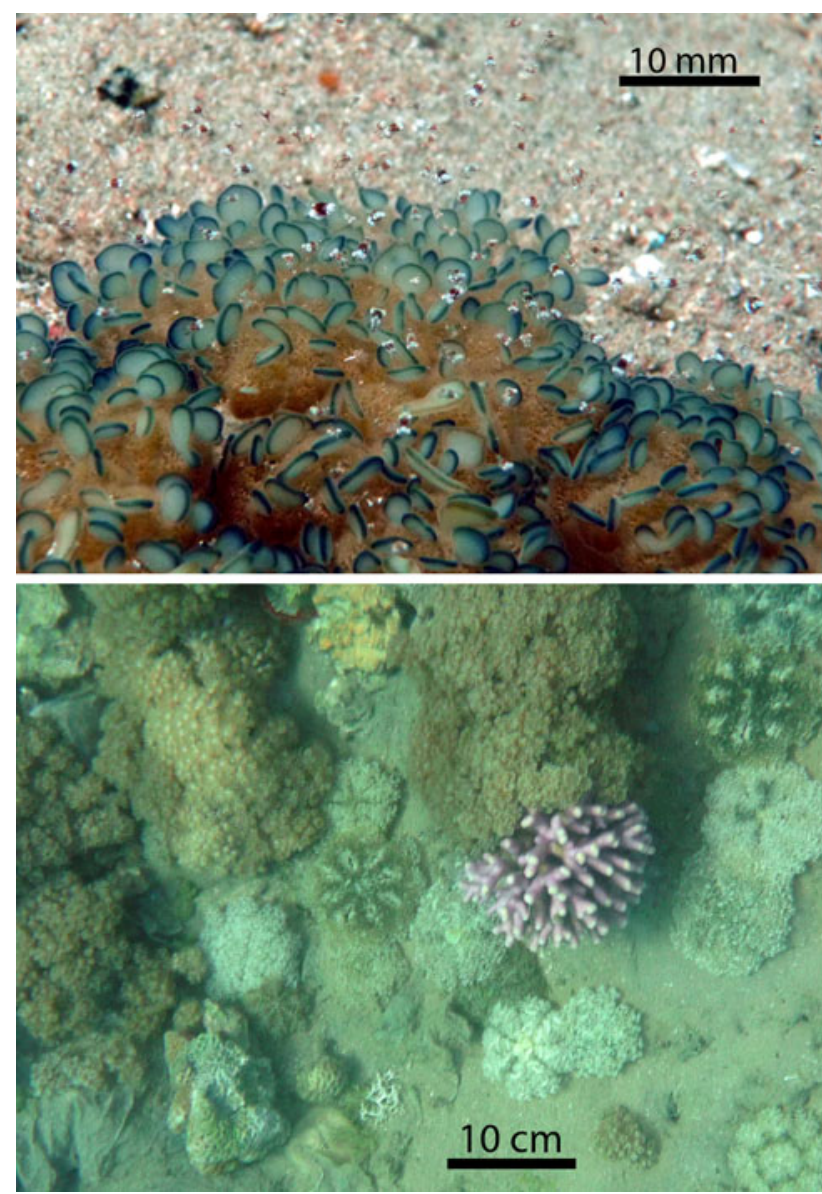

Fig. 2 a Cassiopea sp. exhibiting a swarm of Idiomysis tsurnamali. b High abundance of Cassiopea sp. in the reef habitat

patchy reef structures (19.0\%), areas with high seagrass cover $(10.5 \%)$ and the transition zone $(5.3 \%)$ between reef and sand flats also contributed to the benthic composition in the study area. Artificial constructions, terrigenous stones and carbonate sand flats each accounted for less then $3 \%$ of the study area.

\section{Cassiopea sp. abundance}

Cassiopea sp. exhibited a patchy distribution (Fig. 2b) between and within different benthic habitats, as indicated by the high standard deviations (Table 2). Nevertheless, there were significant (Table 3) differences concerning Cassiopea sp. abundances between the four habitats, ranging from less than one jellyfish $\mathrm{m}^{-2}$ in the seagrass meadow to almost eight jellyfish $\mathrm{m}^{-2}$ in the transition zone (Table 2). Maximum abundance occurred in the reef, exhibiting more than sixfold higher abundances than the seagrass meadow.

Within the entire study area, Cassiopea sp. exhibited a mean abundance of $1.6 \pm 0.3$ with a range from 0 to 22 animals $\mathrm{m}^{-2}(n=71)$.

\section{Cassiopea sp. benthic coverage}

Results obtained from image processing revealed significant differences (Table 3 ) in benthic coverage by Cassiopea sp. between the four main habitats, ranging from less than $1 \%$ in the seagrass meadow to more than $7 \%$ at the transition zone (Table 2). Maximum benthic coverage was reached in the reef habitat, with Cassiopea sp. covering up to $20.1 \%$ of the seafloor.

The seagrass meadow exhibited lowest proportion of unoccupied bare sand flats (Table 2).

Cassiopea sp. benthic coverage in the entire study area was $3.2 \%$ as revealed by line point intercept transect work. There was a strong bias between transects to the north $(6 \%)$ and transects to the south $(0.4 \%)$.

\section{Cassiopea sp. size and association with Idiomysis} tsurnamali

Additional to habitat-specific differences in abundance and benthic coverage, significant habitat-specific differences in jellyfish mean diameter were found. Mean diameter was lowest at the seagrass meadow and highest at the sand flat (Table 2). The percentage of Cassiopea sp. associated with Idiomysis tsurnamali also differed significantly (Table 3) between the habitats, with the highest percentage of associations at the transition zone and lowest jellyfish-mysids association at the seagrass meadow (Table 2).

Furthermore, a correlation between jellyfish diameter and association with mysids was found $(P<0.001)$, with

Table 2 Cassiopea sp. abundance, benthic coverage, diameter and association with Idiomysis tsurnamali in the respective benthic habitat

\begin{tabular}{|c|c|c|c|c|c|c|c|}
\hline Site & $\begin{array}{l}\text { Mean } \\
\text { abundance } \\
\left(\text { animals } \mathrm{m}^{-2}\right)\end{array}$ & $\begin{array}{l}\text { Maximum } \\
\text { abundance } \\
\left(\text { animals m }^{-2}\right)\end{array}$ & $\begin{array}{l}\text { Mean } \\
\text { diameter } \\
(\mathrm{cm})\end{array}$ & $\begin{array}{l}\text { Mean benthic } \\
\text { coverage (\%) }\end{array}$ & $\begin{array}{l}\text { Unoccupied, } \\
\text { bare sand } \\
\text { flats }(\%)\end{array}$ & $\begin{array}{l}\text { Cassiopea- } \\
\text { mysids } \\
\text { association }(\%)\end{array}$ & $\begin{array}{l}\text { Mysids swarm } \\
\text { size distribution } \\
(0: 1: 2: 3)\end{array}$ \\
\hline Reef & $1.6 \pm 2.2$ & 31 & $10.3 \pm 2.3$ & $1.0 \pm 1.1$ & $24 \pm 19$ & 81.5 & 19:30:30:22 \\
\hline Transition zone & $7.9 \pm 6.7$ & 27 & $13.1 \pm 2.7$ & $7.5 \pm 5.8$ & $84 \pm 11$ & 92.9 & $7: 11: 21: 61$ \\
\hline Seagrass meadow & $0.4 \pm 0.8$ & 5 & $8.3 \pm 3.2$ & $0.1 \pm 0.3$ & $8 \pm 9$ & 18.2 & $81: 5: 0: 14$ \\
\hline Sand flat & $1.3 \pm 1.4$ & 14 & $13.5 \pm 2.4$ & $1.6 \pm 1.8$ & $95 \pm 4$ & 61.1 & $39: 14: 8: 39$ \\
\hline
\end{tabular}

Swarm size categories describe abundance of mysids per jellyfish $(0=$ no mysids, $1=0-4$ mysids, $2=5-9$ mysids, $3=$ more than 10 mysids $)$ 
Table 3 Statistical analyses of habitat-specific Cassiopea abundance, benthic coverage and association with mysids

\begin{tabular}{|c|c|c|c|c|c|c|c|c|c|c|c|c|c|c|c|}
\hline & \multicolumn{3}{|c|}{ Mean abundance } & \multicolumn{3}{|c|}{ Benthic coverage } & \multicolumn{3}{|c|}{ Mean diameter } & \multicolumn{3}{|c|}{ Cassiopea-mysids association } & \multicolumn{3}{|c|}{ Mysids swarm size } \\
\hline & $\mathrm{TZ}$ & $\mathrm{SM}$ & SF & $\mathrm{TZ}$ & SM & SF & $\mathrm{TZ}$ & SM & SF & $\mathrm{TZ}$ & SM & SF & $\mathrm{TZ}$ & SM & $\mathrm{SF}$ \\
\hline $\mathrm{RF}$ & $* * *$ & 0.08 & 0.96 & $* * *$ & $*$ & 0.39 & $* * *$ & $* *$ & $* * *$ & 0.21 & $* * *$ & 0.08 & $* *$ & 0.23 & $*$ \\
\hline $\mathrm{TZ}$ & & $* * *$ & $* * *$ & & $* * *$ & $* * *$ & & $* * *$ & 0.56 & & $* * *$ & $* *$ & & 0.93 & 0.71 \\
\hline SM & & & 0.07 & & & $*$ & & & $* * *$ & & & $* *$ & & & 0.81 \\
\hline
\end{tabular}

Given are $P$ values for hypothesis for no differences between respective habitats (TZ transition zone, $S M$ seagrass meadow, $S F$ sand flat, $R F$ reef) concerning listed parameters. $* P<0.05$; ** $P<0.01$; *** $P<0.001$

smaller Cassiopea sp. specimens exhibiting associations to Idiomysis tsurnamali less frequently.

Cassiopea sp. located at the reef exhibited significantly different swarm sizes of Idiomysis tsurnamali compared to those at the transition zone and the sand flat (Tables 2 and 3). Cassiopea sp. swarm sizes were largest within the transition zone. Idiomysis tsurnamali swarm sizes were found to positively correlate with Cassiopea sp. diameter $(P<0.01)$. No habitat-specific differences could be found concerning size classes of Idiomysis tsurnamali specimens themselves.

\section{Discussion}

The findings of the present study characterize Cassiopea to be one of the key organisms within the benthic community in investigated coral reef-associated environments of the Northern Red Sea, exhibiting abundance and benthic coverage comparable to soft corals. On smaller scales, Cassiopea can even act as the dominant benthic organism due to its patchy distribution that further results in habitat-specific differences concerning Cassiopea abundance, size and association patterns to Idiomysis tsurnamali.

These findings complement previous studies (e.g. Collado Vides et al. 1988; Holland et al. 2004; Mergner and Schuhmacher 1981) by describing high Cassiopea abundance in coral reef ecosystems for the first time and indicating active habitat selection potentially controlled by the availability of suitable substrates, inorganic nutrients and prey.

\section{Cassiopea sp. abundance and benthic coverage}

There are only two previous studies in which mean Cassiopea abundance and benthic coverage was quantified. In a fringing reef adjacent to the area investigated in the present study, Mergner and Schuhmacher (1981) observed two Cassiopea sp. specimens in a $25 \mathrm{~m}^{2}$ survey area resulting in an abundance of 0.08 animals $\mathrm{m}^{-2}$ and a benthic coverage of $0.03 \%$. This is much lower than the values observed in the present study. Although the study of Mergner and
Schuhmacher (1981) was conducted during the winter half-year and jellyfish abundances are known to rapidly fluctuate (Pitt et al. 2005), differences to present study likely cannot be ascribed to seasonal changes. Observations during other investigations at the study site (Table 1) indicate a constantly high Cassiopea abundance throughout all seasons over the last 7 years. This is further confirmed by the study of Fitt and Costley (1998), in which no seasonal changes in Cassiopea medusae population were found.

The higher medusae abundance and benthic coverage described in the present study may, therefore, indicate an increase in Cassiopea abundance over the last decades. A second explanation for lower abundances reported by Mergner and Schuhmacher (1981) may be the patchy distribution Cassiopea exhibited (Fig. 2). Mergner and Schuhmacher only investigated a small section of $25 \mathrm{~m}^{2}$, thereby potentially omitting patches with high jellyfish abundances.

The patchy distribution of Cassiopea is further reflected by the significant differences in jellyfish abundance and benthic coverage between the four investigated main habitats (reef, transition zone, sand flat, seagrass meadow). Limited availability of bare sediment likely caused the lowest Cassiopea abundances in the seagrass meadow, which is supported by the findings of Collado Vides et al. (1988). Availability of prey, e.g. copepods or crustacean larvae, which Cassiopea was shown to feed on (Gohar and Eisawy 1960a), may also influence Cassiopea abundance and likely differs between the four habitats. In addition, Cassiopea was shown to actively extract and take up inorganic nutrients from the sediment (Jantzen et al. unpublished). Sites with higher input of organic matter, which is rapidly recycled to regenerate nutrients in permeable reef sands (Wild et al. 2004a, b, 2005) may, therefore, be favoured by Cassiopea specimens. The direct vicinity to reef corals could lead to a high supply of organic matter to the adjacent sediments (Wild et al. 2005) and potentially explain the highest Cassiopea abundances within coral reef-associated habitats (Table 2).

Maximum observed Cassiopea abundance of up to 31 animals $\mathrm{m}^{-2}$ is similar to that observed by Collado Vides et al. (1988), who reported a very high mean abundance of 42 medusae $\mathrm{m}^{-2}$ in Bojórquez lagoon (Mexican Caribbean). 
For coral reef ecosystems, the high abundances observed in present study are described for the first time.

The average benthic cover by Cassiopea sp. of $3.2 \%$ in the study area was lower than described for hermatypic corals (Bouchon-Navaro and Bouchon 1989; Khalaf and Kochzius 2002; Mergner and Schuhmacher 1974) and benthic algae (Haas et al. unpublished), but similar compared to soft corals (Khalaf and Kochzius 2002), thereby characterizing Cassiopea as one of the key representatives of the benthic community. On smaller scales, Cassiopea can even act as the dominant benthic organism in coral reef-associated habitats.

\section{Implications for Cassiopea life cycles}

It is generally reported that Cassiopea is associated with mangrove-dominated habitats (Holland et al. 2004). In this context, Fleck and Fitt (1999) demonstrated in a laboratory study that degrading mangrove leaves provide a natural cue for Cassiopea sp. larval settlement and metamorphosis, whereas settlement on the seagrass Thalassia testudinum only marginally occurred. These findings were supported by in situ observations, which showed that Cassiopea sp. polyps frequently occur on mangrove leaves, but rarely on any other substratum (Fitt 1991; Fitt and Costley 1998). However, in the present study, high abundances of Cassiopea sp. were found more than $150 \mathrm{~km}$ north from the closest mangrove ecosystem (Nabeq, Egypt). As the main current in the Gulf of Aqaba runs from north to south (Berman et al. 2000), it is unlikely that observed high abundances of the almost stationary jellyfish Cassiopea are solely maintained by migration. Therefore, the seagrass meadow (Thalassia testudinum) is suggested to have provided natural cues, e.g. degrading organic material, for larval settlement and metamorphosis sufficient to sustain high abundances. This is further supported by the occurrence of very small medusae of about $1.5 \mathrm{~cm}$ in bell diameter and an estimated age of about 6 weeks (Kaiser, personal communication) and the lowest mean diameters of all four habitats in the seagrass meadow.

When medusae grow, bare substrate becomes limited in the seagrass meadow, which may force the jellyfish to leave. This may deliver an explanation for lowest numbers of medusae in the seagrass meadow despite the provision of natural cues. Highest mean Cassiopea diameter at the sand flat, the habitat with the highest percentage of unoccupied substrate, supports this assumption.

\section{Cassiopea association with Idiomysis tsurnamali}

More than $60 \%$ of all jellyfish exhibited an association to mysids, whereby a positive correlation between jellyfish diameter, the presence of mysids and the mysids swarm size was found. An explanation may be that larger-sized Cassiopea offer more refuge to the mysids, which withdraw between the tentacles in case of danger (Niggl, personal observation). In addition, Cassiopea sp. was found to release organic matter (Ducklow and Mitchell 1979), which is consumed and mineralized by the mysids (Niggl et al. unpublished). As organic matter release by Cassiopea sp. positively correlates with surface area, larger Cassiopea specimens may be able to provide larger mysid swarms with food.

Acknowledgments We thank the staff of the Marine Science Station in Aqaba, especially Dr. Riyad Manasrah, for logistical support on site. Special thanks to Carin Jantzen for the fruitful discussions concerning Cassiopea sp. and for providing valuable input during the manuscript preparation process. Thanks to Andreas Haas and Malik Naumann for their great help in the field. Thanks to Dr. Christian Laforsch for improving the manuscript. Symbols courtesy of the Integration and Application Network, University of Maryland Center for Environmental Science. The study was funded by grant Wi 2677/2-1 of the German Research Foundation (DFG) and a PhD stipend of University of Bavaria/Bavarian Elite Advancement to W. Niggl.

\section{References}

Bacescu M (1973) A new case of commensalism in the Red Sea: the mysid Idiomysis tsurnamali $\mathrm{n} . \mathrm{sp}$. with the Coelenterata Megalactis and Cassiopea. Rev Roum Biol Ser Biol Anim 18:3-7

Berman T, Paldor N, Brenner S (2000) Simulation of wind-driven circulation in the Gulf of Elat (Aqaba). J Mar Syst 26:349-365

Bigelow RP (1900) The anatomy and development of Cassiopea xamachana. Mem Boston Soc Nat Hist 5:191-236

Bischoff A, Fleck J, Hofmann OK (1991) Phorbol esters induce metamorphosis in Cassiopea andromeda and Cassiopea xamachana (Cnidaria: Scyphozoa). Verh Dtsch Zool Ges 84:484

Bolton TF, Graham WM (2006) Jellyfish on the rocks: bioinvasion threat of the international trade in aquarium live rock. Biol Invasions 8:651-653

Bouchon-Navaro Y, Bouchon C (1989) Correlations between chaetodontid fishes and coral communities of the Gulf of Aqaba (Red Sea). Environ Biol Fishes 25:47-60

Çevik C, Erkol IL, Toklu B (2006) A new record of an alien jellyfish from the Levantine coast of Turkey-Cassiopea andromeda (Forsskål, 1775) [Cnidaria: Scyphozoa: Rhizostomea]. Aquat Invasions 1:196-197

Collado Vides L, Segura Puertas L, Merino Ibarra M (1988) Observaciones sobre dos escifomedusas del género Cassiopea en la Laguna de Bojórquez, Quintana Roo, México. Rev Investig Mar 9:21-27

Curtis SK, Cowden RR (1971) Normal and experimentally modified development of buds in Cassiopea (phylum Coelenterata, class Scyphozoa). Acta Embryol Exp 3:239-259

Ducklow HW, Mitchell R (1979) Composition of mucus released by coral reef coelenterates. Limnol Oceanogr 24:706-714

English S, Wilkinson C, Baker V (1994) Survey manual for tropical marine resources. Australien Institute Of Marine Science, Townsville

Fitt WK (1984) The role of chemosensory behavior of Symbiodinium microadriaticum, intermediate hosts, and host behavior in the infection of coelenterates and molluscs with zooxanthellae. Mar Biol 81:9-17

Fitt WK (1991) Natural metamorphic cues of larvae of a tropical jellyfish. Am Zool 31:106 
Fitt WK, Costley K (1998) The role of temperature in survival of the polyp stage of the tropical rhizostome jellyfish Cassiopea xamachana. J Exp Mar Biol Ecol 222:79-91

Fleck J, Fitt WK (1999) Degrading mangrove leaves of Rhizophora mangle Linne provide a natural cue for settlement and metamorphosis of the upside down jellyfish Cassiopea xamachana Bigelow. J Exp Mar Biol Ecol 234(1):83-94

Gohar HAF, Eisawy AM (1960a) The biology of Cassiopea andromeda (from the Red Sea). Publ Mar Biol Stn Ghardaqa 11:4-42

Gohar HAF, Eisawy AM (1960b) The development of Cassiopea andromeda (Scyphomedusae). Publ Mar Biol Stn Ghardaqa 11:148-190

Hofmann OK, Kremer BP (1981) Carbon metabolism and strobilation in Cassiopea andromeda (Cnidaria: Scyphozoa): significance of endosymbiotic dinoflagellates. Mar Biol 65:25-33

Hofmann DK, Neumann R, Henne K (1978) Strobilation, budding and initiation of scyphistoma morphogenesis in the rhizostome Cassiopea andromeda (Cnidaria: Scyphozoa). Mar Biol 47:161-176

Holland BS, Dawson MN, Crow GL, Hofmann DK (2004) Global phylogeography of Cassiopea (Scyphozoa: Rhizostomeae): molecular evidence for cryptic species and multiple invasions of the Hawaiian Islands. Mar Biol 145:1119-1128

Khalaf MA, Kochzius M (2002) Community structure and biogeography of shore fishes in the Gulf of Aqaba, Red Sea. Helgol Mar Res $55: 252-284$

Ludwig F (1969) Die Zooxanthellen bei Cassiopea andromeda, Eschscholtz 1829 (Polyp Stadium) und ihre Bedeutung fur die Strobilation. Zool Jb (Abt Anat Ontog Tiere) 86:238-277

Mayer AG (1910) Medusae of the World Volume III. The Scyphomedusae. Carnegie Institution of Washington, Washington

Mergner H, Schuhmacher H (1981) Quantitative analyse der Korallenbesiedlung eines Vorriffareals bei Aqaba (Rotes Meer). Helgol Meeresunters 34:337-354

Mergner H, Schuhmacher H (1974) Morphologie, Ökologie and Zonierung von Korallenriffen bei Aqaba, (Golf von Aqaba, Rotes Meer). Helgol Meeresunters 26:238-358

Mills CE (2001) Jellyfish blooms: are populations increasing globally in response to changing ocean conditions? Hydrobiol 451:55-68

Özgür E, Öztürk B (2008) A population of the alien jellyfish, Cassiopea andromeda (Forsskål, 1775) [Cnidaria: Scyphozoa: Rhizostomea] in the Ölüdeniz Lagoon, Turkey. Aquat Invasions 3:423-428
Panucci-Papadopoulou M, Zenetos A, Corsini-Foka M, Politou C (2005) Update of marine alien species in Hellenic waters. Mediterr Mar Sci 6:147-158

Pitt KA, Koop K, Rissik D (2005) Contrasting contributions to inorganic nutrient recycling by the co-occurring jellyfishes, Catostylus mosaicus and Phyllorhiza punctata (Scyphozoa, Rhizostomeae). J Exp Mar Biol Ecol 315:71-86

Purcell JE, Uye S, Lo W (2007) Anthropogenic causes of jellyfish blooms and their direct consequences for humans: a review. Mar Ecol Prog Ser 350:153-174

Rahat M, Adar O (1980) Effect of symbiotic zooxanthellae and temperature on budding and strobilation in Cassiopeia andromeda (Eschscholz). Biol Bull 159:394-401

Smith HG (1936) Contribution to the anatomy and physiology of Cassiopea frondosa. Pap Tortugas Lab 31:18-52

Thieme C, Hofmann DK (2003a) An endogenous peptide is involved in internal control of metamorphosis in the marine invertebrate Cassiopea xamachana (Cnidaria: Scyphozoa). Dev Genes Evol 213:97-101

Thieme C, Hofmann DK (2003b) Control of head morphogenesis in an invertebrate asexually produced larva-like bud (Cassiopea andromeda; Cnidaria: Scyphozoa). Dev Genes Evol 213:127-133

Thornhill DJ, Daniel MW, LaJeunesse TC, Schmidt GW, Fitt WK (2006) Natural infections of aposymbiotic Cassiopea xamachana scyphistomae from environmental pools of Symbiodinium. J Exp Mar Biol Ecol 338:50-56

Todd BD, Thornhill DJ, Fitt WK (2006) Patterns of inorganic phosphate uptake in Cassiopea xamachana: a bioindicator species. Mar Poll Bull 52:515-521

Wild C, Huettel M, Klueter A, Kremb S, Rasheed M, Joergensen B (2004a) Coral mucus functions as an energy carrier and particle trap in the reef ecosystem. Nature 428:66-70

Wild C, Rasheed M, Werner U, Franke U, Johnstone R, Huettel M (2004b) Degradation and mineralization of coral mucus in reef environments. Mar Ecol Prog Ser 267:159-171

Wild C, Rasheed M, Jantzen C, Cook P, Struck U, Boetius A (2005) Benthic metabolism and degradation of natural particulate organic matter in carbonate and silicate reef sands of the Northern Red Sea. Mar Ecol Prog Ser 298:69-87 